\title{
Splenomegaly and hypersplenism in hepatic vena cava syndrome
}

\author{
Santosh Man Shrestha \\ Liver Foundation Nepal, Sitapaela Height Nagarjun Municipality, Kathmandu, Nepal
}

\begin{abstract}
Background and Aim: Hepatic vena cava syndrome (HVCS) is a bacterial infection-induced obliterative disease of the inferior vena cava at the site of the hepatic vein openings that causes chronic liver disease with a high incidence of liver cirrhosis and a moderate incidence of hepatocellular carcinoma (HCC). HVCS typically manifests clinically as recurrent mild jaundice and/or a mild elevation of transaminases or ascites as a result of hepatic venous outflow obstruction. This study is an investigation of the complications and treatment results of a large cohort of HVCS patients with an emphasis on splenomegaly and hypersplenism.
\end{abstract}

Materials and Methods: A total of 1935 (1335 male and 600 female) patients with HVCS seen between 2004 and 2019 for splenomegaly and hypersplenism were enrolled in this retrospective study. The incidence of splenomegaly, ascites, cirrhosis, HCC, and other complications was measured and analyzed.

Results: Long-term follow-up of a large study group seen over several years indicated that $16 \%$ had mild splenomegaly, and $50 \%$ of these developed cytopenia commonly thrombocytopenia and/or leucopenia.

Conclusion: The development of hypersplenism was related to recurrent or prolonged acute exacerbation of HVCS. This resulted in an increased incidence of ascites and cirrhosis as well as complications, such as hepatic encephalopathy, gastrointestinal or mucosal bleeding, or mortality.

Keywords: Ascites; bacterial infection; cytopenia; hepatocellular carcinoma; liver cirrhosis; thrombocytopenia.

\section{Introduction}

Splenomegaly is a frequent finding in patients with liver disease, and it is an important sign of portal hypertension. Some $36 \%$ to $92 \%$ of patients with cirrhosis have splenomegaly. ${ }^{[1]}$ Some patients with splenomegaly due to cirrhosis or other causes develop thrombocytopenia, neutropenia, or anemia, either alone or in combinations. This condition is called hyper-

How to cite this article: Shrestha SM. Splenomegaly and hypersplenism in hepatic vena cava syndrome. Hepatology Forum 2021; 2(2):69-75.

Received: April 14, 2021; Accepted: April 20, 2021; Available online: May 24, 2021

Corresponding author: Santosh Man Shrestha; Liver Foundation Nepal Sitapaela Height Nagarjun Municipality, Kathmandu, Nepal

Phone: +977-9841 237 627; e-mail: smshrestha1938@gmail.com

(C) OPEn ACCESS

C. This work is licensed under a Creative Commons Attribution-NonCommercial 4.0 International License.

(C) Copyright 2021 by Hepatology Forum - Available online at www.hepatologyforum.org splenism, a term first introduced by Chauffard in 1907. ${ }^{[2]}$ Hypersplenism is characterized by a peripheral blood picture of cytopenia, splenomegaly, normal or hypercellular bone marrow, and a return of the peripheral blood picture to near normal after a splenectomy. However, fulfillment of all of these criteria is not necessary for the diagnosis. Practical criteria that defined hypersplenism as splenomegaly with a platelet count of $<150.000$ / $\mu \mathrm{L}$ and/or a white blood cell (WBC) count of $<3500 / \mu \mathrm{L}$ were suggested by Liangpunsakul et al. ${ }^{[3]}$ in 2003 and have largely been adopted.

Hypersplenism, or an overactive spleen, is a well-established syndrome. Banti ${ }^{[4]}$ first described a disorder characterized by anemia and splenomegaly not related to any hematological disorder in 1898 . Osler ${ }^{[5]}$ reported on a group of patients with chronic splenomegaly and anemia without cirrhosis but with recurrent gastrointestinal hemorrhage that improved after splenectomy in 1900. Subsequently, a condition called noncirrhotic portal fibrosis, characterized by portal hypertension in the absence of cirrhosis, occurring with splenomegaly and hypersplenism was reported by authors in India, Japan, and elsewhere. ${ }^{[6,7]}$ This paper describes splenomegaly and hypersplenism in hepatic vena cava syndrome (HVCS).

HVCS is a chronic liver disease related to an obstructive lesion of the site of the inferior vena cava (IVC) opening to the hepatic veins. Previously, the disease was described as membranous obstruction of the inferior vena cava or Budd-Chiari syndrome and was most often observed in Asia and Africa ${ }^{[8-16]}$ and less frequently in Europe and the USA. ${ }^{[17-22]}$ It was considered a rare congenital disease ${ }^{[23]}$ and diagnosed by cavogram or at autopsy on detection of a membrane in the IVC at the level of the diaphragm. Okuda and other authors established that the obliterative lesion was a sequela of thrombosis, now known to be caused by bacterial infection. ${ }^{[24-27]}$ The disease has been observed even in a well-anticoagulated patient. ${ }^{[22]}$ A pathogenesis based on bacterial infection was established, and the disease was renamed HVCS. ${ }^{[28]}$ It was separated from other causes of hepatic venous outflow obstruction (HVOO), such as sinusoidal obstruction syndrome and Budd-Chiari syndrome. ${ }^{[29]} \mathrm{Im}$ portant features of these 3 HVOO diseases are provided in Table 1.

A junction is formed where the IVC meets the hepatic vein openings between the parts fixed to the diaphragm and the distal free segment, and this site is vulnerable to endothelial damage and infection. ${ }^{[30]} \mathrm{Ca}-$ vographic study indicated that the changes seen in the early stages of the disease included mild stenosis of the IVC following thrombophlebitis and the development of cava-caval collateral pathways. [31] Subsequent bacterial infections caused acute exacerbation (AE) with deposition of a thrombus at the site of extension into the ostia of the hepatic veins and downward along the posterior wall of the IVC. Thrombosis formed during AE leads to conversion of the lesion into marked stenosis or a thick, narrowed obstruction. ${ }^{[32,33]}$ Intrahepatic vein thrombosis can result in intimal thickening, segmental stenosis, 
Table 1. Classification of primary hepatic venous outflow obstruction

\begin{tabular}{|c|c|c|c|}
\hline Particulars/Types & Sinusoidal obstruction syndrome & Budd-Chiari syndrome & Hepatic vena cava syndrome \\
\hline Primary site of lesion & Sinusoidal endothelium & Hepatic veins & Hepatic portion of IVC \\
\hline Secondary site/s & Terminal hepatic vein & $\mathrm{PV} / \mathrm{IVC}$ & HV ostia/ HV/PV \\
\hline Etiology & $\begin{array}{l}\text { Toxic injury } \\
\text { - Pyrrolizidine alkaloids } \\
\text { - Immunosuppressive drugs }\end{array}$ & $\begin{array}{l}\text { Prothrombotic disorders } \\
\text {-Thrombosis }\end{array}$ & $\begin{array}{l}\text { Bacterial infection } \\
\text {-Thrombophlebitis }\end{array}$ \\
\hline Clinical & $\begin{array}{l}\text { Acute: hepatomegaly, ascites, } \\
\text { jaundice mild/moderate/severe }\end{array}$ & $\begin{array}{l}\text { Acute/subacute/ } \\
\text { Chronic/rarely } \\
\text { Fulminant }\end{array}$ & $\begin{array}{l}\text { Chronic with recurrent } \\
\text { acute exacerbations \& } \\
\text { Cavo-caval collaterals }\end{array}$ \\
\hline
\end{tabular}

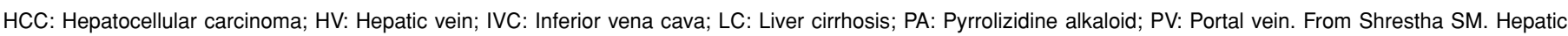
Venous Outflow Obstruction: Suggestion of a New Classification. J Ren Hepat Disord 2017,1(2):41-51, printed with permission.

or the formation of membrane or calcification. A large thrombus in the IVC at or near the mouth of the hepatic veins during the acute stage or AE can result in ascites due to HVOO.${ }^{[29]}$ Ascites and occasional pleural effusion that occur in HVCS are associated with the simultaneous development of bacterial peritonitis. ${ }^{[34,35]}$

Thrombosis of the hepatic veins can cause sinusoidal hypertension and ischemic liver damage around the terminal hepatic veins. Accumulation of parenchymal extinction results in the development of cirrhosis. ${ }^{[36,37]}$ One study reported an incidence of cirrhosis and hepatocellular carcinoma (HCC) in patients with HVCS of $78 \%$ and $10 \%$, respectively, and it was noted that the development was related to the severity and frequency of $\mathrm{AE}$ and not the duration of the disease or the severity of caval obstruction. ${ }^{[38]}$

Ultrasonography and color Doppler (US/CD) examination of the IVC and the liver is now the established method to diagnose the disease. ${ }^{[39-41]}$ Localized intimal thickening or stenosis of the IVC at the site of the hepatic vein junction and an abnormal blood flow pattern that is vein-biphasic or continuous rather than triphasic constitutes the basic criteria for diagnosis (Fig. 1a, b).

\section{Materials and Methods}

HVCS is defined as chronic disease of hepatic venous out flow obstruction where the initial obstructive lesion occurs in the IVC at the site of the hepatic vein openings and extension of the obstructive lesion into the intrahepatic veins during subsequent $\mathrm{AE}$ precipitated by clinical or subclinical bacterial infection. The disease is characterized by a long asymptomatic course and recurrent AE that manifests clinically as mild jaundice and/or mild elevation of transaminases or ascites.

This retrospective analysis included 1935 (1335 male and 600 female) patients with HVCS seen between 2004 and 2019 for splenomegaly and hypersplenism. The protocol of this study was approved by the review board of our institution. Patients with fever, jaundice, upper abdomen discomfort, or with detected hepatomegaly, splenomegaly, ascites, dilated superficial veins in the trunk, or elevated levels of transaminases

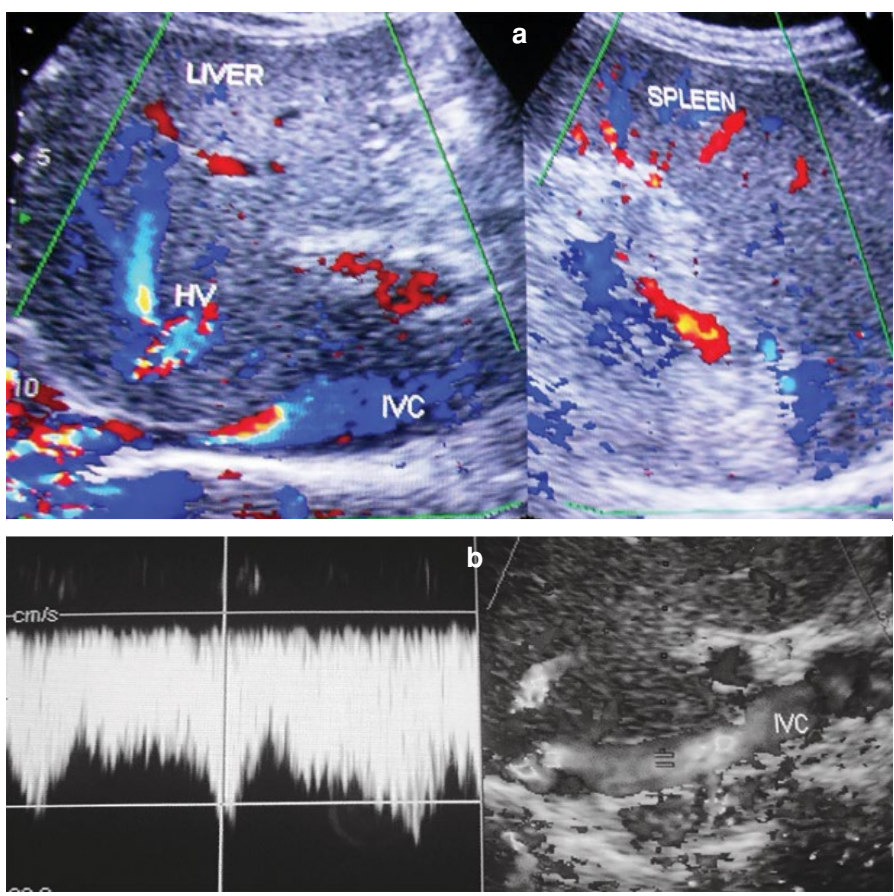

Figure 1. (a) Ultrasonography with color Doppler imaging is the best means to diagnose hepatic vena cava syndrome and mild splenomegaly. The inferior vena cava (IVC) shows marked stenosis with a thick posterior wall at the site of hepatic vein (HV) opening. Obstruction of blood flow is visible at the outlets of the HV and the IVC. (b) Abnormal blood flow pattern- a continuous pattern, rather than triphasic, is diagnostic of hepatic vena cava syndrome.

observed in a routine check-up underwent a US/CD examination of the IVC and liver for a diagnosis of HVCS. Patients with a history of alcohol abuse or with a positive hepatitis B surface antigen or anti-HCV finding were excluded. Patients with an alanine aminotransferase (ALT)/aspartate aminotransferase (AST) level at or more than 5 times the upper 
limit of normal were tested for anti-hepatitis A virus immunoglobulin (Ig) M for acute hepatitis A infection, and anti-hepatitis E virus IgM for hepatitis E infection, and those with positive results were also excluded.

HVCS patients had routine hematology tests that included a total and differential WBC count, platelet count, hemoglobin level, erythrocyte sedimentation rate (ESR), and routine liver tests to measure bilirubin, ALT, AST, alkaline phosphatase, protein, albumin, and C-reactive protein (CRP), and/or blood culture and tests to assess urea, creatinine and electrolyte levels. Patients with an elevated level of serum bilirubin and/or ALT/AST with a high CRP level and/or neutrophil leukocytosis or a neutrophil concentration of $>70 \%$ were considered to be in an $\mathrm{AE}$ state of the disease. Patients with these features who developed ascites and/or pleural effusion were diagnosed with severe AE. The presence of ascites and/or pleural effusion was ascertained with US (Fig. 2). A diagnosis of bacterial peritonitis in 43 patients seen during the early period was made based on ascetic fluid analysis findings of a high absolute neutrophil count and/or aerobic organisms in culture. ${ }^{[34]}$ In the later period, diagnosis was ascertained using US, as it provided information sooner and was found to be equally sensitive. Acute peritonitis was diagnosed on the detection of free-floating particles or membranes in the ascites, and chronic peritonitis on the observation of a thick peritoneum with adhesions or loculations.

A history of jaundice and the detection of organized thrombi of different ages along the posterior wall of the IVC, intimal thickening, stenosis, membrane or calcified foci in the intrahepatic veins, collateral pathways in and around the liver, and/or a thick layer of perihepatitis around the liver or a thick-walled gallbladder observed with US/CD confirmed prior episodes of AE.

Diagnosis of mild splenomegaly was also performed with US/CD examination. ${ }^{[42]} \mathrm{CD}$ allowed for visualization of thrombosis in the splenic veins and detection of a splenorenal shunt. Hypersplenism was diagnosed in patients with a platelet count of $<150.000 / \mu \mathrm{L}$ and or a WBC count of $<4000 / \mu \mathrm{L}$ with/without anemia (hemoglobin $<10$ $\mathrm{g} / \mathrm{dL}$ ). Twelve patients with thrombocytopenia underwent a bone marrow biopsy. The presence of cirrhosis was ascertained based on a US/CD examination of the liver and observation of increased coarse echotexture of the liver parenchyma with an irregular surface and a rounded edge. Upper gastrointestinal endoscopy examination for esophageal varices was performed for 42 patients with severe AE. Other investigations included a CT scan of the abdomen in 20 patients, assay for auto-antibodies and iron and cupper studies in some patients with cirrhosis and alpha fetoprotein in patients with space-occupying lesions. Patients were seen each month until symptoms subsided and then at 6 months and yearly intervals. The follow-up period was 1 year or less in 816 patients (42\%), 1 to 6 years in $362(18.7 \%)$, and 7 to 26 years in $100(5 \%)$ US/CD and routine blood tests were repeated at follow-up visits. The incidence of major complications of the disease, such as ascites and cirrhosis, was compared between patients with and without splenomegaly and the validity was verified with a Z-test.

\section{Results}

The HVCS patients were largely asymptomatic and manifested clinically with mild jaundice and/or minimal-to-mild ALT elevations precipitated by fever, gut, or urinary tract infection, surgery or other invasive procedures. In a few, ascites and edema of the legs or a puffy face followed in the subsequent weeks. HVCS was diagnosed in all age

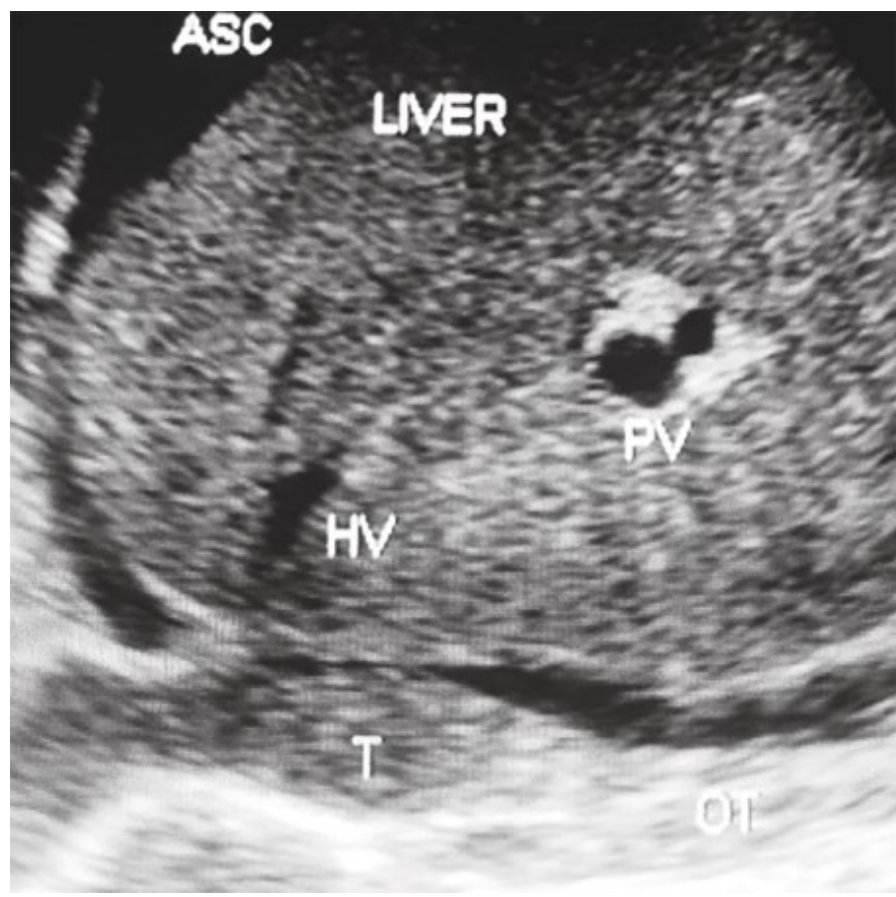

Figure 2. Severe acute exacerbation of hepatic vena cava syndrome: A recent large thrombus (T) and an older, organized thrombus (OT) can be seen in a stenosed inferior vena cava (IVC) with thick posterior wall at the site of hepatic vein opening resulting in hepatomegaly and ascites from hepatic venous outflow obstruction. The peritoneal wall is thick, indicating the presence of chronic peritonitis.

ASC: Ascites; HV: Hepatic vein; PV: Portal vein.

groups, with a high incidence in the second and third decades of life and a greater incidence in males (Table 2).

Severe AE with ascites and/or pleural effusion (Fig. 1b) occurred in 194 patients $(10 \%)$. Ascites was moderate in the majority, and minimal in 25. It was associated with pleural effusion in 12 patients, whereas in 10 , ascites was not detectable. A thick layer of perihepatitis around the liver was observed in 9, which was indicative of a previous episode. Ascites was associated with simultaneous development of bacterial peritonitis in all of the patients. The ascitic fluid protein level was $>2.5 \mathrm{~g}$, a serum-ascites albumin gradient of $>1.1$, and organism growth in cultures were seen in 32 of 45 patients. The organisms isolated were Escherichia coli in 14, Klebsiella species in 9, and Staphylococcus aureus in 9 cases. A blood culture performed for 44 patients with a fever revealed aerobic organisms in 17 patients (38.6\%): Klebsiella species in 7, Escherichia coli in 9, and Staphylococcus aureus in 1.

Splenomegaly was detected by US in 317 patients (16\%) (38\% female and $62 \%$ male). The spleen was palpable below the costal margin only in $48(2.2 \%)$. About $50 \%$ of the palpable spleens were in those $<20$ years of age, with the highest incidence of $64 \%$ seen in infants. Splenomegaly preceded the development of cirrhosis. CD illustrated the presence of splenic vein thrombosis in many. A splenorenal shunt was observed in 4 and confirmed with a CT scan in 3, and of these, 1 patient suffered from recurrent episodes of portal-systemic encephalopathy. Endoscopy revealed small varices in 2 patients. The spleen of a patient with long-standing disease exhibited increased echotexture with a diffuse presence of linear echoic structure that suggested fibrosis due to thrombosed splenic veins (Fig. 3). 
Table 2. Age groups of patients with hepatic vena cava syndrome (2004-2019) indicating the incidence of ascites and liver cirrhosis in patients with splenomegaly

\begin{tabular}{lllll} 
& & & & Among patients with splenomegaly (\%) \\
\cline { 5 - 5 } Age groups & HVCS (\%) & Splenomegaly (\%) & Ascites & Cirrhosis \\
\hline $0-9$ years & 134 & $31(23.1)$ & $8(25.8)$ & $12(38.7)$ \\
$10-19$ years & 292 & $53(18.1)$ & $5(9.4)$ & $16(30.1)$ \\
$20-29$ years & 521 & $66(12.6)$ & $13(19.6)$ & $14(21.2)$ \\
$30-39$ years & 398 & $41(10.3)$ & $4(9.7)$ & $7(17.0)$ \\
$40-49$ years & 236 & $39(16.5)$ & $11(28.2)$ & $13(33.3)$ \\
$50-59$ years & 172 & $37(21.5)$ & $14(37.8)$ & $21(56.7)$ \\
$60-69$ years & 109 & $30(27.5)$ & $16(53.3)$ & $19(63.3)$ \\
$70-79$ years & 63 & $17(26.9)$ & $12(70.5)$ & $12(70.5)$ \\
$80-89$ years & 10 & $2(20.0)$ & $2(100.0)$ & $1(50.0)$ \\
Total & 1935 & $316(16.3)$ & $85(26.8)$ & $115(36.3)$ \\
\hline
\end{tabular}

HVCS: Hepatic vena cava syndrome.

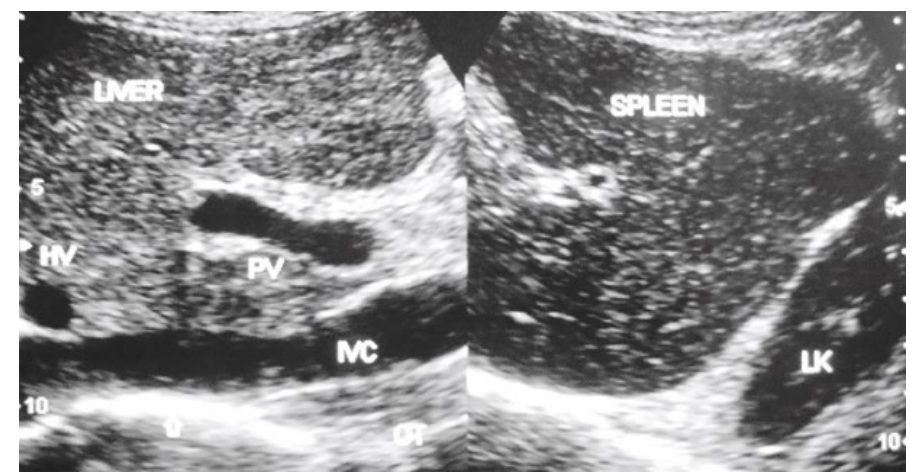

Figure 3. Ultrasonogrpahy image of a patient with long-standing hepatic vena cava syndrome. The interior vena cava (IVC) has a very thick echoic posterior wall with a thick layer of old, organized thrombus. The liver is cirrhotic and the spleen shows increased echo-texture and a diffuse presence of echoic foci, indicative of fibrosis due to thrombosed hepatic veins. HV: Hepatic vein; PV: Portal vein; OT: Organized thrombus; LK: Left kidney.

Hypersplenism: Cytopenia was detected in 50\% of the patients with splenomegaly. Persistent cytopenia was also observed in 29 patients without splenomegaly, 1 of whom had early cirrhosis, a prominent splenic vein, and spontaneous splenorenal shunt.

Among the patients with hypersplenism, thrombocytopenia occurred in 137 (78\%), leucopenia in 118 (67\%), and anemia in 46 (26\%). Thrombocytopenia alone was observed in 40 , leucopenia in 30 , and anemia in 8 . Thrombocytopenia and leucopenia was seen in 59; thrombocytopenia, leucopenia, and anemia in 29; and thrombocytopenia and leucopenia in 9. Patients with leucopenia had frequent episodes of $\mathrm{AE}$, and 15 patients $(8 \%)$ with thrombocytopenia had evidence of spontaneous bleeding: gastrointestinal hemorrhage in 10, epistaxis in 4, ecchymosis or petechiae in 2, and bleeding from another site, hematuria and rectal bleeding each occurred in 1 patient. Upper gastrointestinal endoscopy performed in 42 patients with severe AE showed no varices in 11 $(25 \%)$, mild varices grade I to II in $21(50 \%)$, and severe grade III to IV varices in $10(25 \%)$. Variceal bleeding in patients with hypersplenism was mild and self-limiting, and was recurrent in 4 with low-grade varices. Mortality in HVCS was related to persistent ascites and jaundice in patients with hypersplenism.
A bone marrow biopsy was performed in 12 patients with thrombocytopenia. The result was normal or showed hypercellular marrow with erythroid and megakaryocytic hyperplasia. These 12 patients had initially presented at the hematology clinic and were treated for idiopathic thrombocytopenia (ITP). Subsequent detection of ascites and/or jaundice and transaminases elevation led to a diagnosis of HVCS.

Evolution of hypersplenism: Past episodes of AE were indicated by a history of jaundice or the presence of old, organized thrombi of different ages in the IVC. A history of jaundice was seen in 120 out of 317 patients (37.8\%) with splenomegaly, compared with 545 of 1618 (33.6\%) without splenomegaly. Jaundice was recurrent in $46.6 \%$ with splenomegaly compared with $34.4 \%$ in patients without splenomegaly. Patients with splenomegaly and/or hypersplenism had a thick layer of organized thrombi of different ages along the posterior wall of the IVC. The occurrence of splenomegaly and hypersplenism was related to prolonged or recurrent $\mathrm{AE}$ and not to the duration of the disease or the age of the patient. The phenomenon was observed in infants as well as in elderly patients.

In the early phase, $\mathrm{AE}$ was associated with neutrophil leukocytosis and was more marked in infants. The response in patients with recurrent AE was varied, some had mild neutrophil leukocytosis, others had a normal WBC count with a neutrophil percentage of $>70 \%$ and some failed to respond and had a persistent low WBC count of approximately 4000/cu mm.

Consequences of splenomegaly and hypersplenism in HVCS: Patients with splenomegaly and hypersplenism had a greater frequency of $\mathrm{AE}$ and the incidence of ascites was 4 times greater than that of patients without splenomegaly. Similarly, the incidence of cirrhosis was 2.8 times greater. Patients with splenomegaly and hypersplenism also had a greater incidence of anemia as well as complications like skin-related bleeding and/or mucosal or gastrointestinal bleeding and hepatic encephalopathy.

Cirrhosis in HVCS: Evidence of cirrhosis was observed in 322 patients (16.6\%). In 104 cases it developed rapidly, within a few months of the appearance of ascites. Some developed features of cirrhosis while ascites was still present. All of these patients exhibited CD evidence of HVOO. Iron and cupper assays and studies of auto-antibodies of 44 patients with cirrhosis were normal. The recurrence of ascites in cirrhotic patients may also be due to HVOO and respond to medical treatment with antibiotics and diuretics. ${ }^{[43]}$ Two cirrhotic patients in this series with recurrent jaundice and ascites who had gone to India for 
treatment had a liver transplantation. Both died, one within 10 days of the procedure while in the hospital and another within 6 months following the recurrence of jaundice and ascites. Eleven patients in this series had a nodular, space-occupying lesion in the liver, 9 were diagnosed with HCC based on a CT scan, alpha fetoprotein assay, and fine-needle aspiration cytology results, and 3 had regenerative nodules.

\section{Discussion}

HVCS is endemic in Nepal, and is a common cause of cirrhosis and HCC. ${ }^{[38,44,45]}$ In this study, splenomegaly was detected in $16 \%$ of the HVCS patients. In 1959, Parker ${ }^{[46]}$ reported that among a large series of autopsied cases of hepatic vein occlusion from the UK, all of the idiopathic cases had a lesion in the hepatic portion of the IVC consistent with HVCS, and 30\% had splenomegaly. Similarly, in Japan, Nakamura et al. ${ }^{[8]}$ detected splenomegaly in $32 \%$ of 107 autopsied cases. Case reports of the disease have also mentioned of occurrence of splenomegaly, ${ }^{[9,17,19]}$ and hypersplenism. ${ }^{[47,48]}$ The comparatively low prevalence of splenomegaly in this case series is likely because this complication occurred only in patients with severe prolonged or recurrent AE.

The splenomegaly observed in HVCS in this study was mild, and was best detected with US/CD examination. A palpable spleen was present only in a few, mainly young, patients. The average weight of a normal spleen in adults is 150 g. ${ }^{[49]}$ In reported HVCS cases it has been described as mild or double the normal size. ${ }^{[18,19,25]}$ In 49 autopsied cases, the weight of the spleen in $75 \%$ was $<400 \mathrm{~g}$, ${ }^{[46]}$ whereas in cases of cirrhosis with portal hypertension it weighed between $200 \mathrm{~g}$ and $850 \mathrm{~g}$, with an average of $450 \mathrm{~g} .^{[50]}$

An interesting observation was the detection of a spontaneous splenorenal shunt in some patients. It was associated with the presence of mild, non-progressive esophageal varices and recurrent episodes of hepatic encephalopathy in 2 patients. Development of a spontaneous splenorenal shunt has been described in patients with advanced portal hypertension, ${ }^{[51]}$ including after endoscopic sclerotherapy of esophageal varices resulting in no recurrence of esophageal varices. ${ }^{[52]}$

Cause of splenomegaly in HVCS: The spleen is an important immunological organ and a circulation filter. It synthesizes IgG and clears the blood of microorganisms, particulate antigens, and weak red blood cells. The spleen is richly supplied with reticuloendothelial cells and lymphoid tissue, and includes a mechanism to slow microcirculation in the form of sheathed arteries and a sphincter at the entrance and exits of the venous sinuses. ${ }^{[53]}$ The spleen plays an active role in fighting bacterial infection. Functional hyperactivity induced by prolonged or recurrent bacterial infections is a probable cause of splenomegaly and hypersplenism in HVCS. Histology of an enlarged spleen in HVCS has revealed congestion, increased fibrosis of the trabeculae and thrombosis of the splenic vein and its tributaries. ${ }^{[25]}$ In cases of portal hypertension, passive venous congestion may be the cause of splenomegaly, but there is a poor correlation between portal venous pressure and the size of the spleen. ${ }^{[54]}$ Histopathology of the spleen in portal hypertension showed an increased number of trabeculae, hyperplasia of the venous sinuses, increased proliferation and activity of macrophages in the red pulp, and an increased quantity of T and B cells with intense phagocytosis in the germinal centers of the white pulp. ${ }^{[54]}$ These observations suggested that immunological stimulation may contribute to splenomegaly in instances of portal hypertension as well as passive congestion.

Hypersplenism in HVCS: Hypersplenism was observed in $50 \%$ of the patients with splenomegaly. This hematological condition also developed in a few without splenomegaly. Different combinations of cytope- nia occurred; the most common were thrombocytopenia and neutropenia. Platelet counts varied from just below normal values to $<10.000 /$ $\mu \mathrm{L}$. It was associated with petechiae ecchymosis, or epistaxis in a few, which led to their first presentation at the hematology clinic where they were treated for ITP. ITP is a common differential diagnosis of HVCS patient with thrombocytopenia. The diagnosis of ITP is based on the exclusion of known causes of thrombocytopenia. It is characterized by the presence of a high proportion of large, reticulated platelets and a high thrombopoietin level in the blood, whereas in hypersplenism, the circulating platelets are usually small and old, and the blood thrombopoietin level is normal or low. The spleen contains young, hemostatically active platelets, which are released at times of stress. ${ }^{[55]}$

Cytopenia was observed after the development of splenomegaly; however, a fluctuation in low platelet and/or WBC counts was measured for some years before a count considered sufficiently diagnostic was established. Therefore, instead of a fixed cell count, a persistent or fluctuating low level may indicate the presence of hypersplenism in HVCS. Patients with hypersplenism had varied reactions to bacterial infection. Neutrophil leukocytosis occurred in the early stage, but later, the WBC count remained normal or low, with a neutrophil concentration of $>70 \%$. A few, especially infants, demonstrated an increase in WBC count, but neutropenia persisted. Some patients failed to respond to bacterial infection and a diagnosis of $\mathrm{AE}$ was then based on elevated levels of CRP, transaminases, and the ESR.

Long-term follow-up demonstrated that the prevention of bacterial infection or its immediate treatment resulted in a return of a nearly normal blood picture in some patients. Though a significant inverse relationship between the size of the spleen and the platelet count has been described in portal hypertension, ${ }^{[56]}$ observation among HVCS patients suggested no consistent correlation between splenic size and thrombocytopenia, and some patients with a palpable spleen continued to have a normal blood picture, while a few patients with persistent thrombocytopenia or leucopenia had no splenomegaly.

Mechanism of development of hypersplenism: Aster's study ${ }^{[57]}$ using chromium $^{51}$ platelets showed that the thrombocytopenia in hypersplenism was due to sequestration of platelets in the enlarged spleen. A normal spleen stores about $30 \%$ to $45 \%$ of the circulating platelet pool, and this figure can be as much as $90 \%$ in a patient with splenomegaly. The large network of venous sinuses with a mechanism to slow microcirculation may play a role in the storage of platelets. In addition, platelet survival may also may be reduced in hypersplenism. It has been reported that the mean platelet survival in a cirrhotic patient with splenomegaly was 5.8 days, compared with 9.5 days in normal control subjects. ${ }^{[58]}$ Platelet-associated immunoglobulin (PAIgG) is believed to render platelets susceptible to immune-related destruction via the reticuloendothelial system. In cirrhotic patients with portal hypertension, the PAIgG level is increased, and this level is correlated with reduced platelet survival. In a patient with liver disease and hypersplenism, platelet production may also be impaired. Thrombopoietin is produced by the liver. Platelets have receptors for thrombopoietin. In thrombocytopenia, free-circulating thrombopoietin increases and stimulates platelet production. As liver disease progresses, the level of free thrombopoietin may fall and fail to stimulate platelet production.

Radiolabeled studies have suggested that neutropenia in hypersplenism may also be due to increased sequestration that may occur under conditions of stress, like exercise or infection. ${ }^{[59]}$ Myeloperoxidase is present in the granules of neutrophils, and is released on activation or degradation. The elevated level detected in patients with splenomeg- 
aly suggested that, in addition to splenic pooling, there may also be increased destruction of neutropenia. Anemia is seen less frequently in hypersplenism. Red cell pooling in the spleen may account for 5\% to $40 \%$ of the total red cell mass. The size of the splenic pool increases with splenomegaly, but there is no close correlation. Recurrent bleeding from varices or other sites may also contribute to anemia.

Consequences of hypersplenism: Patients with neutropenia are vulnerable to bacterial infection, which can result in frequent and/or severe $\mathrm{AE}$. The incidence of severe AE with ascites/pleural effusion was fourfold greater in patients with splenomegaly. Patients with thrombocytopenia are likely to bleed with the development of varices and the onset of ascites. Bleeding seen in this study was often mild, self-limiting, and recurrent. Some patients with thrombocytopenia presented with mucosal and skin bleeding, most commonly epistaxis and petechiae or ecchymosis. Another complication observed was episodes of portal-systemic encephalopathy seen in patient with a hepatorenal shunt. ${ }^{[60]}$ Of the 4 patients with a splenorenal shunt, 3 , including 1 with portal-systemic encephalopathy, had features of early cirrhosis and mild esophageal varices. Development of this complication was most probably related to sinusoidal hypertension induced by hepatic vein obstruction.

There are questions about the ability to reverse hypersplenism. Containment of blood cells in the spleen appears to be reversible. Patients with leucopenia as a result of hypersplenism were observed to have neutrophil leukocytosis during severe AE. Similarly, a release of platelets has been reported in stress conditions or with an intravenous infusion of adrenalin. ${ }^{[57]}$ A normal blood count and undetectable splenomegaly despite the presence of cirrhosis 10 to 18 years later in 4 patients with a history of hypersplenism indicated that hypersplenism in HVCS is reversible. Early effective management of AE and prevention of further episodes of AE can successfully reverse hypersplenism.

Cirrhosis due to HVCS: The incidence cirrhosis in HVCS is very high. [8,12,38] The pathogenesis of cirrhosis in HVCS is well established. ${ }^{[36,37]}$ Briefly, the sinusoidal hypertension that follow hepatic vein obstruction causes a series of physiological events, including extravasation of blood into the space of Disse and between liver cell plates, and the reflex reduction of hepatic arterial flow, which combine to cause hemorrhagic necrosis of hepatocytes around the terminal hepatic venules. The accumulation of focal areas of hepatic extinctions caused by thrombosis of small branches of hepatic veins or sudden massive ischemic liver damage following thrombotic obstruction of all of the large hepatic veins at or near its outlets in the IVC resulted in cirrhosis. At a molecular level, hypoxic liver damage causes a release of vascular endothelial growth factor (VEGF), which acts on VEGF receptors I and II in endothelial cells, causing a release of hepatocyte growth factor and interleukin 6 , the induction of angiogenesis, and deposition of collagen due to the activation of hepatic stellate cells, which combine to promote the development of liver cirrhosis. ${ }^{[61]}$

In Nepal, HVCS was a common comorbid condition in cirrhotic patients with chronic hepatitis $\mathrm{B}$ or $\mathrm{C}$ virus infection and a history of alcohol abuse. ${ }^{[62]}$ In such circumstances, identification of the exact cause of cirrhosis becomes important. HVCS-induced cirrhosis can be recognized by rapid onset following the development of ascites and the presence of any or all of the following changes: dilated hepatic veins with obstruction of blood flow at the outlet; intimal thickening; stenosis, membrane development, or calcification of the intrahepatic veins; a thick layer of perihepatitis around the liver; or a thick gallbladder wall. [63] The compensated stage of liver cirrhosis in HVCS can be lengthy. Recurrence of ascites may also be due to HVOO that responded to medical treatment and not hepatic decompensation.

\section{Conclusion}

HVCS can be an important cause of splenomegaly and hypersplenism. It is associated with an increased incidence of complications, ascites, cirrhosis, and increased mortality.

Since the prevalence of HVCS is related to poor community hygiene, it may be endemic in many developing countries. US/CD examination of the IVC and the liver is recommended for all liver patients, especially those who present with jaundice, intermittent mild elevation of transaminases, thrombocytopenia, or leukopenia.

Ethics Committee Approval: Liver Foundation Research Ethic Committee approval (date: 02.04 .2021 , no: 20/01/2077/89).

Peer-review: Externally peer-reviewed.

Conflict of Interest: The authors have no conflict of interest to declare.

Financial Disclosure: The authors declared that this study has received no financial support.

\section{References}

1. Mutchnick MG, Lerner E, Conn HO. Effect of portacaval anastomosis on hypersplenism. Dig Dis Sci 1980;25(12):929-938.

2. Chauffard M. Apropos de la communication de M Vaquez. Bull Mem Soc Med Hop Paris 1907;24:1201-1203.

3. Liangpunsakul S, Ulmer BJ, Chalasani N. Predictors and implications of severe hypersplenism in patients with cirrhosis. Am J Med Sci 2003;326(3):111116.

4. Banti G. Splenomegalie mit Leberizirrhose. Beitr Pathol Anat Allg Pathol 1898;24:21-33.

5. Osler W. On splenic anemia. Am J Med Sci 1900;119:54-73.

6. Basu AK, Boyer J, Bhattacharya R, Mallik KC, Sen Gupta KP. Non-cirrhotic portal fibrosis with portal hypertension: a new syndrome. I. Clinical and function studies and results of operations. Indian J Med Res 1967;55(4):336-350.

7. Okuda K, Nakashima T, Kameda H, Sugiura M, Ohnishi K, Kobayashi M. Japan Ministry of Health and Welfare Committee on Idiopathic Portal hypertension. Idiopathic non cirrhotic portal hypertension: A national study. In: Brunner H, Thaler H (editors). Hepatology : A Festschrift for Hans Popper. New York: Raven, 1985. p. 95-108.

8. Nakamura T, Nakamura S, Aikawa T, Suzuki O, Onodera A, Karoji N. Obstruction of the inferior vena cava in the hepatic portion and the hepatic veins. Report of eight cases and review of the Japanese literature. Angiology 1968;19(8):479-498.

9. Ono J, Sakoda K, Kawada T. Membranous obstruction of the inferior vena cava. Ann Surg 1983;197(4):454-458.

10. Datta DV, Saha S, Singh SA, Gupta BB, Aikat BK, Chhuttani PN. Clinical spectrum of Budd-Chiari syndrome in Chandigrah with particular reference to obstruction of intrahepatic portion of inferior vena cava. Indian J Med Res 1972;60(3):385-402.

11. Victor S, Jayanthi V, Madanagopalan N. Coarctation of the inferior vena cava. Trop Gastroenterol 1987;8(3):127-142.

12. Dilawari JB, Bambery P, Chawla Y, Kaur U, Bhusnurmath SR, Malhotra HS, et al. Hepatic outflow obstruction (Budd-Chiari syndrome). Experience with 177 patients and a review of the literature. Medicine (Baltimore) 1994;73(1):21-36.

13. Wang ZG. Management of Budd-Chiari syndrome: experience from 430 cases. Asian J Surg 1996;19:23-30.

14. Bronte-Stewart B, Goetz RH. Budd-Chiari syndrome: high inferior vena caval obstruction demonstrated by venography. Angiology 1952;3:167-178.

15. Simson IW. Membranous obstruction of the inferior vena cava and hepatocellular carcinoma in South Africa. Gastroenterology 1982;82(2):171-178.

16. Kew MC, McKnight A, Hodkinson J, Bukofzer S, Esser JD. The role of membranous obstruction of the inferior vena cava in the etiology of hepatocellular 
cases. Johns Hopkins Hospital Report 1911;16:363-548.

18. Osler W. Obliteration of vena cava inferior, with great stenosis of orifices of hepatic veins. J Anat Physiol 1879;13(3):291-304.

19. Rigdon RH. On the relation between the thrombophlebitis of the inferior vena cava and occlusion of the hepatic veins. Bull Johns Hopkins Hosp 1933;53:162-171.

20. Kibel MA, Marsden HB. Inferior vena caval and hepatic vein thrombosis: the Chiari syndrome in childhood. Arch Dis Child 1956;31(157):225-228.

21. Havlioglu N, Brunt EM, Bacon BR. Budd-Chiari syndrome and hepatocellular carcinoma: a case report and review of the literature. Am J Gastroenterol 2003;98(1):201-204. [CrossRef]

22. Hatab H, Mohammed F, Stockwell R, McMurtry H. Membranous Budd-Chiari syndrome in a well-anticoagulated patient. BMJ Case Rep 2010;2010:bcr0520102990. [CrossRef]

23. Hirooka M. Membranous obstruction of the hepatic portion of the inferior vena cava. Presumtive theory based on developmental abnormality. Acta Hepatologica Japonica 1969;6:566-577. [CrossRef]

24. Kage M, Arakawa M, Kojiro M, Okuda K. Histopathology of membranous obstruction of the inferior vena cava in the Budd-Chiari syndrome. Gastroenterology 1992;102(6):2081-2090. [CrossRef]

25. Takaishi Y, Asada M, Kimura K, Nagao K, Okuda K. Kondo Y, et al. Aetiology of membranous obstruction of the inferior vena cava: congenital or acquired? Gastroenterology International 1990;3(2):70-80.

26. Okuda K, Kage M, Shrestha SM. Proposal of a new nomenclature for BuddChiari syndrome: hepatic vein thrombosis versus thrombosis of the inferior vena cava at its hepatic portion. Hepatology 1998;28(5):1191-1198. [CrossRef]

27. Shrestha SM, Shrestha S. Hepatic vena cava disease: Etiologic relation to bacterial infection. Hepatol Res 2007;37(3):196-204. [CrossRef]

28. Shrestha SM, Kage M, Lee BB. Hepatic vena cava syndrome: New concept of pathogenesis. Hepatol Res 2017;47(7):603-615. [CrossRef]

29. Shrestha SM. Hepatic venous outflow obstruction: suggestion of a new classification. J Renal Hepat Disord 2017;1(2):41-51. [CrossRef]

30. Kretz R. Pathologie der leber. Ergeballg Pathol Ant 1902;82:473-485.

31. Shrestha SM, Joshi BL, Shrestha S, Maharajan KG. Cavographic study of an early stage of obstruction of the hepatic portion of the inferior vena cava. $\mathrm{J}$ Gastroenterol Hepatol 2000;15(2):202-210.

32. Terebayashi H, Okuda K, Nomura F, Ohnishi K, Wong P. Transformation of inferior vena caval thrombosis to membranous obstruction in a patient with lupus anticoagulant. Gastroenterology 1986;91:219-224.

33. Blanshard C, Dodge G, Pasi J, Ormiston M, Dick R, Burroughs AK. Membranous obstruction of inferior vena cava in a patient with factor $\mathrm{V}$ Leiden: evidence for a post-thrombotic aetiology. J Hepatol 1997;26(3):731-735.

34. Shrestha SM, Shrestha S. Bacterial peritonitis in the hepatic inferior vena cava disease: A hypothesis to explain the cause of infection in high protein ascites. Hepatology Research 2002;24(1):42-49.

35. Shrestha SM. Pleural effusion in hepatic vena cava disease. Kathmandu University Med J 2007;5:218-224.

36. Wanless IR. Pathogenesis of cirrhosis. J Gastroenterol Hepatol 2004;19:S369371 .

37. Shrestha SM. Sinusoidal hypertension: a cause of liver cirrhosis in developing countries. Austin J Gastroenterology 2017:4(3):1085-1092.

38. Shrestha SM. Liver cirrhosis and hepatocellular carcinoma in hepatic vena cava disease, a liver disease caused by obstruction of inferior vena cava. Hepatol Int 2009;3(2):392-402.

39. Shrestha SM. Diagnosis of Hepatic Vena Cava Syndrome by ultrasonography and color Doppler based on new concept of its pathogenesis. EC Gastroenterology and Digestive System 2017;2(1):256-270.

40. Bolondi L, Gaiani S, Bassi SL, Zironi G, Bonino F, Brunetto M, et al. Diagnosis of Budd-Chiari syndrome by pulsed Doppler ultrasound. Gastroenterology 1999;100:1324-13331.

41. Chawla Y, Kumar S, Dhiman RK, Suri S, Dilawari JB. Duplex Doppler sonography in patients with Budd-Chiari syndrome. J Gastroenterol Hepatol 1999;14(9):904-907. [CrossRef]

42. Morali GS, Blendis LM. Splenomegaly in portal hypertension: causes and effects. In: Okuda K, Benhamou JP, editors. Portal Hypertension. 1991. p. 85-99.

43. Shrestha SM. Medical management of hepatic vena cava syndrome (Based on new concept of its pathogenesis). Japanese Journal of Gastroenterology and Hepatology 2019;1:1-9.

44. Shrestha SM, Okuda K, Uchida T, Maharjan KG, Shrestha S, Joshi BL, et al. Endemicity and clinical picture of liver disease due to obstruction of the hepatic portion of the inferior vena cava in Nepal. J Gastroenterol Hepatol.1996;11(2):170-179. [CrossRef]

45. Shrestha SM, Shrestha S. Hepatic vena cava syndrome: a common cause of liver cirrhosis in children in Nepal. Trop Gastroenterol 2014;35(2):85-95.

46. Parker RG. Occlusion of the hepatic veins in man. Medicine (Baltimore) 1959;38:369-402. [CrossRef]

47. Kımura C, Shırotanı H, Hırooka M, Terada M, Iwahashı K, Maetanı S. Membranous obliteration of the inferior vena cava in the hepatic portion. (Review of 6 cases with 3 autopsies). J Cardiovasc Surg (Torino) 1963;4:87-98.

48. Liu Z, Cheng J, Song Z, Sun J. Pathology and surgical treatment of BuddChiari syndrome. China: Proceedings of the First International Symposium on Budd-Chiari Syndrome; 1988. p. 3-5.

49. Krumbharr EB, Lippincott SW. The postmortem weight of the normal human spleen at different ages. Am J Med Scie 1939;197: 344-349. [CrossRef]

50. Moschcowitz E. The pathogenesis of splenomegaly in hypertension of portal circulation: "Congestive splenomegaly". Medicine 1948;27(2):187-221.

51. Wexler MJ, MacLean LD. Massive spontaneous portal-systemic shunting without varices. Arch Surg 1975;110(8):995-1003. [CrossRef]

52. Dilawari JB, Raju GS, Chawla YK. Development of large splenoadrenorenal shunt after endoscopic sclerotherapy. Gastroenterology 1989;97:421-426.

53. Knisely MH. Spleen studies. I Microscopic observations of the circulatory system of living unstimulated mammalian spleen. Anat Rec 1936;65(1):23.

54. Kito H. Experimental study on splenomegaly after partial hepatectomy. Nippon Geka Gakkai Zasshi 1987;88:1604-1618.

55. Karpatkin S, Freedman ML. Hypersplenic thrombocytopenia differentiated from increased peripheral destruction by platelet volume. Ann Intern Med 1978;89(2):200-203. [CrossRef]

56. el-Khishen MA, Henderson JM, Millikan WJ Jr, Kutner MH, Warren WD. Splenectomy is contraindicated for thrombocytopenia secondary to portal hypertension. Surg Gynecol Obstet 1985;160(3):233-238.

57. Aster RH. Pooling of platelets in the spleen: role in the pathogenesis of "hypersplenic" thrombocytopenia. J Clin Invest 1966;45(5):645-657. [CrossRef]

58. Stein SF, Harker LA. Kinetic and functional studies of platelets, fibrinogen and plasminogen in patients with hepatic cirrhosis. J Lab Clin Med 1982;99:217230.

59. Allsop P, Peters AM, Arnot RN, Stuttle AW, Deenmamode M, Gwilliam ME, et al. Intrasplenic blood cell kinetics in man before and after brief maximal exercise. Clin Sci (Lond) 1992;83(1):47-54. [CrossRef]

60. Conn HO. The hepatic encephalopathies. In: Conn HO, Bircher J, editors. Hepatic Encephalopathy: Syndromes and therapies. Illinois: Medi-Ed Press; 1994. p. 1-12.

61. Corpechot C, Barbu V, Wendum D, Kinnman N, Rey C, Poupon R, et al. Hypoxia-induced VEGF and collagen I expressions are associated with angiogenesis and fibrogenesis in experimental cirrhosis. Hepatology 2002;35(5):10101021. [CrossRef]

62. Shrestha SM, Shrestha S, Shrestha A, Tsuda F, Endo K, Takahashi M, et al. High prevalence of hepatitis $\mathrm{B}$ virus infection and inferior vena cava obstruction among patients with liver cirrhosis or hepatocellular carcinoma in Nepal. J Gastroenterol Hepatol 2007;22(11):1921-1928. [CrossRef]

63. Shrestha SM. Liver cirrhosis in hepatic vena cava syndrome (or membranous obstruction of inferior vena cava). World J Hepatol 2015;7(6):874-884. 